\title{
Deformation-induced nanocrystallization: A comparison of two amorphous Al-based alloys
}

\author{
W.H. Jiang \\ Department of Nuclear Engineering and Radiological Sciences, University of Michigan, \\ Ann Arbor, Michigan 48109 \\ F.E. Pinkerton \\ General Motors R \& D Center, Warren, Michigan 48090 \\ M. Atzmon \\ Department of Nuclear Engineering and Radiological Sciences, and Department of Materials Science \\ and Engineering, University of Michigan, Ann Arbor, Michigan 48109
}

(Received 23 October 2004; accepted 10 December 2004)

Using conventional and high-resolution transmission electron microscopy (HRTEM), the effects of rolling at room temperature on the microstructures of amorphous $\mathrm{Al}_{90} \mathrm{Fe}_{5} \mathrm{Gd}_{5}$ and $\mathrm{Al}_{86.8} \mathrm{Ni}_{3.7} \mathrm{Y}_{9.5}$ were compared. In rolled $\mathrm{Al}_{90} \mathrm{Fe}_{5} \mathrm{Gd}_{5}$, nanocrystallites were observed at shear bands, whereas none were observed in rolled $\mathrm{Al}_{86.8} \mathrm{Ni}_{3.7} \mathrm{Y}_{9.5}$. When HRTEM was combined with with Fourier transform filtering, nanoscale, low-density defects were imaged. In $\mathrm{Al}_{90} \mathrm{Fe}_{5} \mathrm{Gd}_{5}$, the shear bands contain few defects, which are concentrated at the boundary zone between the shear bands and undeformed region, whereas in $\mathrm{Al}_{86.8} \mathrm{Ni}_{3.7} \mathrm{Y}_{9.5}$, the shear bands contain a uniform distribution of defects with a density higher than the undeformed region. The preferential precipitation of nanocrystallites in rolled $\mathrm{Al}_{90} \mathrm{Fe}_{5} \mathrm{Gd}_{5}$ is attributed to a kinetic effect due to uniformly-distributed excess free volume in the shear bands.

\section{INTRODUCTION}

Recently, mechanically induced nanocrystallization in amorphous alloys, achieved by ball milling, ${ }^{1-3}$ bending, ${ }^{4,5}$ rolling, ${ }^{6}$ tension, ${ }^{7,8}$ and nanoindentation, ${ }^{9,10}$ has received much attention. The process of mechanically induced nanocrystallization is of potential practical significance for the synthesis of amorphous-nanocrystallite composites and their processing and service. In addition, the mechanisms of atomic displacement and formation of crystalline phases under plastic deformation are of significant fundamental interest.

To date, no consensus concerning the microscopic mechanism of mechanically induced nanocrystallization has been reached. Since atomic mobility is very sluggish, it has been suggested that a temperature rise may play a crucial role in their formation. ${ }^{11}$ Recently, we combined nanoindentation with transmission electron microscopy (TEM) to study the effect of deformation at a low strain rate on amorphous $\mathrm{Al}_{90} \mathrm{Fe}_{5} \mathrm{Gd}_{5}$ alloy, to rule out a temperature rise during deformation. The results indicated that mechanical deformation at or near room temperature led to the precipitation of nanocrystalline $\mathrm{Al} .{ }^{10}$ Furthermore,

DOI: $10.1557 / J M R .2005 .0090$ our work also demonstrated that the stress state is an important factor in mechanically induced nanocrystallization of an amorphous alloy. Nanocrystallization occurred only in the predominantly compressive region of a sample bent at room temperature. ${ }^{12}$ Mechanically induced nanocrystallization appears to be a general phenomenon, since it has been observed in $\mathrm{Al}-, \mathrm{Zr}-$, and Fe-based alloys. ${ }^{1-12}$ However, this process is composition dependent; it may vary between otherwise similar alloys. ${ }^{1,4}$

Mechanically induced nanocrystallization occurs exclusively at shear bands, which are the main microstructural response to plastic deformation in amorphous alloys. They are usually identified and characterized morphologically using a scanning electron microscope (SEM). However, little information is available on their atomic structure, as the relatively small differences between them and the undeformed matrix are frequently undetectable by TEM. Recently, Miller and Gibson ${ }^{13}$ have developed a quantitative high-resolution transmission electron microscopy (HRTEM) method of characterizing the medium-range atomic structure of amorphous solids. This method includes quantitative analysis of electron images and their Fourier amplitudes, essentially combining small-angle scattering analysis and high-resolution imaging from the same microscopic 
region. It has led to the identification of nanometer-scale voids in amorphous silica thin films. Utilizing this method, Li et al. ${ }^{14}$ studied shear bands in bulk, Zr-based, metallic glasses and found that they contained a higher concentration of nanometer-scale voids than the undeformed regions. A correlation of the structure of shear bands in amorphous Al-based alloys with the presence or absence of mechanically induced nanocrystallites is especially significant in the present context.

The present work employs quantitative HRTEM to examine nanoscale defects at shear bands of rolled amorphous $\mathrm{Al}_{90} \mathrm{Fe}_{5} \mathrm{Gd}_{5}$ and $\mathrm{Al}_{86.8} \mathrm{Ni}_{3.7} \mathrm{Y}_{9.5}$ alloys, of which only the former contains mechanically induced nanocrystallites. ${ }^{1}$ The results are used to elucidate the mechanism of mechanically induced nanocrystallization in an amorphous alloy, confirming the mechanism we have previously proposed.

\section{EXPERIMENTAL}

Two amorphous Al-based alloys, $\mathrm{Al}_{90} \mathrm{Fe}_{5} \mathrm{Gd}_{5}$ and $\mathrm{Al}_{86.8} \mathrm{Ni}_{3.7} \mathrm{Y}_{9.5}$ (at.\%), were used in the present work. Alloy ingots were prepared by arc melting a mixture of the constituent elements in a purified argon atmosphere. Amorphous ribbons $(1 \times 0.022 \mathrm{~mm})$ were prepared from the master-alloy ingots using a single-roller meltspinning apparatus. A Cr-plated copper wheel with a tangential velocity of $40 \mathrm{~m} / \mathrm{s}$ was used in either vacuum or an Ar atmosphere. X-ray and electron diffraction analyses were used to confirm the amorphous structure of the as-spun alloy ribbons.

As-spun ribbons were rolled at room temperature in up to 100 small steps to a final thickness reduction of $45.5 \%$. TEM specimens were prepared electrolytically using a single-side jet-thinning electropolisher from the wheel side of the ribbons, in a solution of $25 \%$ nitric acid and $75 \%$ methanol at $243 \mathrm{~K}$ and a voltage of $90 \mathrm{~V}$. The samples were investigated using a JEOL 2010F HRTEM (Tokyo, Japan) at an operating voltage of $200 \mathrm{kV}$. The HRTEM images were collected on a charge-coupled device (CCD) camera and their further processing was performed digitally. The instrumental camera length was used for lattice-parameter determination from diffraction patterns.

We performed a set of observations aimed at ruling out an artifact due to atomic displacements by the electrons in the TEM. We observed no detectable change in the microstructure of shear bands at a magnification of $100 \mathrm{~K}$ for constant exposure to the electron beam up to $30 \mathrm{~min}$. All the results we report were obtained by avoiding placement of the focused beam on one location for a prolonged time. Our conventional-resolution observations were generally performed at a magnification not higher than $100 \mathrm{~K}$ for less than $5 \mathrm{~min}$. Selected-area electron diffraction (SAED) patterns, showing nanocrystallization at shear bands, were obtained in 1 or $2 \mathrm{~min}$.

\section{RESULTS AND DISCUSSION}

Rolling resulted in the formation of numerous shear bands in both the amorphous $\mathrm{Al}_{90} \mathrm{Fe}_{5} \mathrm{Gd}_{5}$ and $\mathrm{Al}_{86.8} \mathrm{Ni}_{3.7} \mathrm{Y}_{9.5}$ ribbons, indicating inhomogeneous plastic deformation. Typical microstructures morphologies of rolled amorphous alloys are shown in Fig. 1. The shear band appears brighter than the undeformed region, which is a result of a thickness contrast; as they have less resistance to chemical attack during thinning, the shear bands are thinned at a higher rate than the matrix. ${ }^{15}$ In rolled $\mathrm{Al}_{90} \mathrm{Fe}_{5} \mathrm{Gd}_{5}$, an SAED pattern, obtained from a region containing a shear band, shows four sharp diffraction rings plus diffuse rings originating from the amorphous matrix, indicating the occurrence of crystallization [Fig. 2(a) inset]. The sharp rings were indexed as $\{111\},\{200\},\{220\}$, and $\{311\}$, respectively, of a

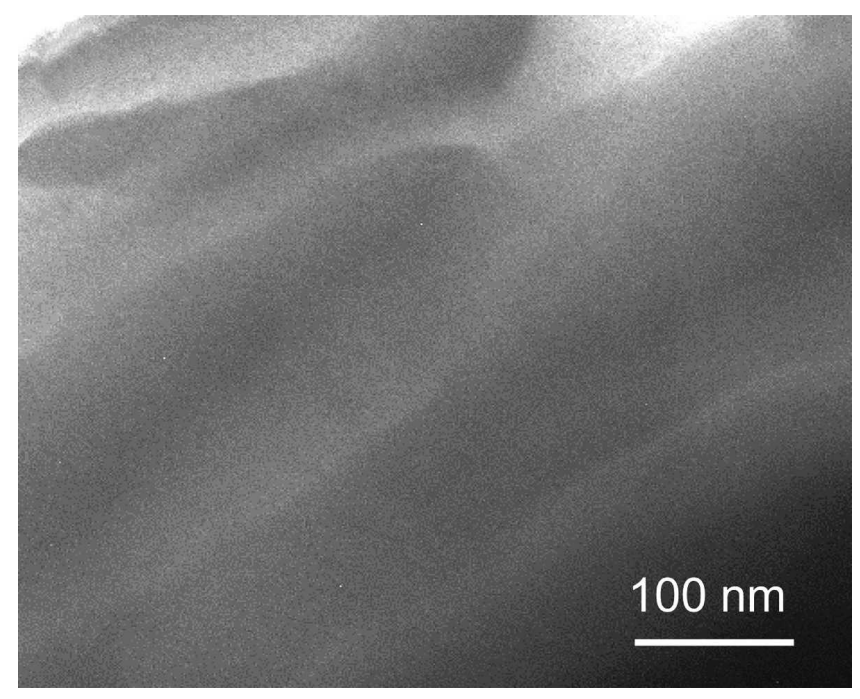

(a)

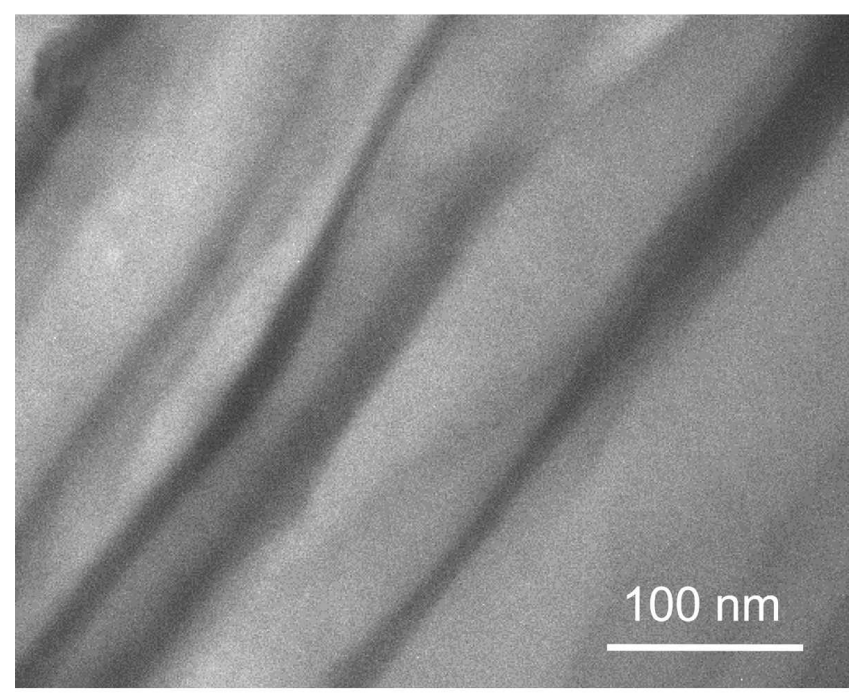

(b)

FIG. 1. TEM bright-field images of rolled amorphous (a) $\mathrm{Al}_{90} \mathrm{Fe}_{5} \mathrm{Gd}_{5}$ and (b) $\mathrm{Al}_{86.8} \mathrm{Ni}_{3.7} \mathrm{Y}_{9.5}$. 


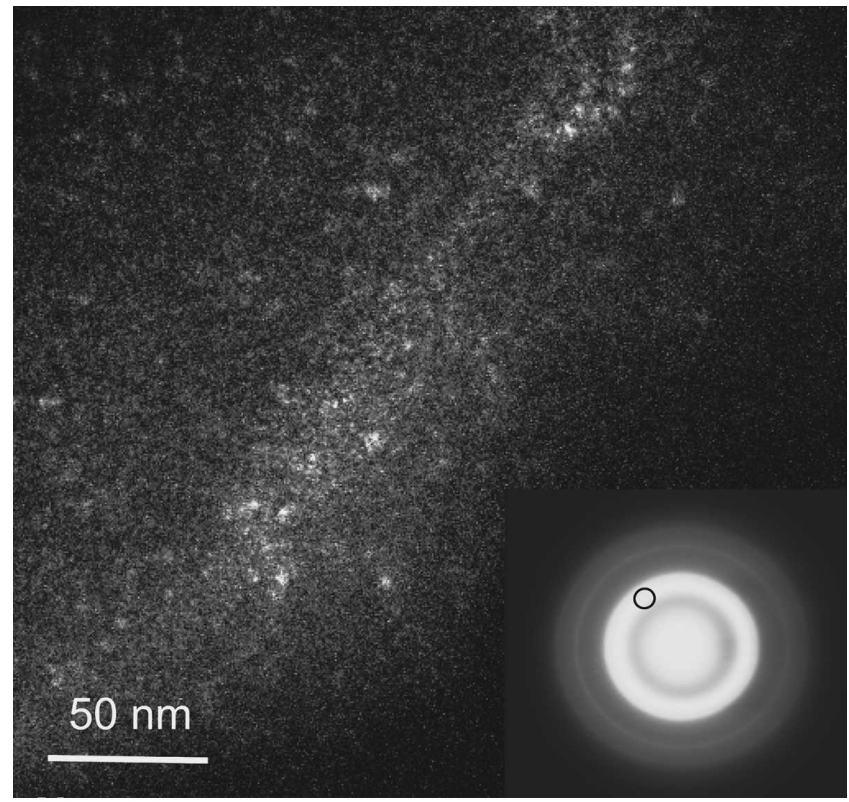

(a)

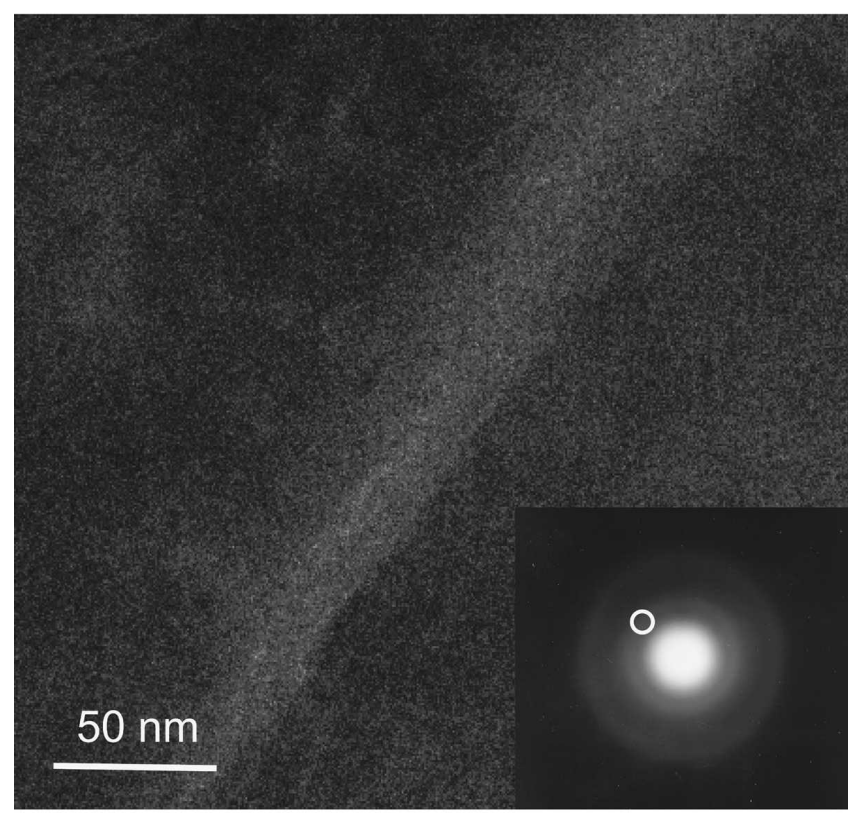

(b)

FIG. 2. TEM dark-field images of rolled amorphous (a) $\mathrm{Al}_{90} \mathrm{Fe}_{5} \mathrm{Gd}_{5}$ and (b) $\mathrm{Al}_{86.8} \mathrm{Ni}_{3.7} \mathrm{Y}_{9.5}$. Insets are the corresponding SAED patterns, in which the location of the objective aperture is illustrated schematically.

face-centered-cubic (fcc) phase with a lattice constant of $0.405 \mathrm{~nm}$, as compared with $0.40414 \mathrm{~nm}$ for pure $\mathrm{Al} .{ }^{16} \mathrm{~A}$ dark-field image [Fig. 2(a)] reveals nanocrystallites at a shear band. This demonstrates that rolling at room temperature induced nanocrystallization in $\mathrm{Al}_{90} \mathrm{Fe}_{5} \mathrm{Gd}_{5}$. In rolled $\mathrm{Al}_{86.8} \mathrm{Ni}_{3.7} \mathrm{Y}_{9.5}$, the SAED pattern [Fig. 2(b) inset] contained diffuse halos but no sharp rings. Furthermore, dark-field micrographs [Fig. 2(b)], obtained from the same region of Fourier space as Fig. 2(a), revealed no crystallites.

Following the method developed by Miller and Gibson, ${ }^{13}$ and later extended by $\mathrm{Li}$ et al., ${ }^{14}$ the nanoscale structural characteristics of the shear bands in the rolled samples were investigated. First, images were obtained at a defocus value of around $-200 \mathrm{~nm}$. This maximizes the intensity for the relevant range of spatial frequencies (see below) ${ }^{14}$ while avoiding a potential artifact due to contrast reversal. Fourier transforms of the images were computed. We detected a prominent difference in the Fourier-transform amplitude between the shear band and undeformed region in the small-angle scattering region, similar to the results of $\mathrm{Li}$ et al. ${ }^{14}$ Similar results were also obtained by Donovan and Stobbs, using axially aligned dark-field images for amorphous $\mathrm{Ni}_{76} \mathrm{P}_{24}$ and $\mathrm{Fe}_{40} \mathrm{Ni}_{40} \mathrm{~B}_{20}{ }^{17}$ To image the defects giving rise to the small-angle scattering, the Fourier transform was filtered by passing the spatial frequencies of interest $(0.5<k<$ $1.5 \mathrm{~nm}^{-1}$ ) and excluding all other spatial frequencies (see Li et al. ${ }^{14}$ ). A reverse Fourier transform was then calculated to obtain a filtered image, which displays the projected atomic density. It does not contain contributions from the sample's thickness variations since these have long wavelengths, thus the uniform mesoscopically averaged intensity. Regions with locally lower density appear bright; those with higher density appear dark. ${ }^{14}$ To identify density fluctuations that exceed those expected statistically in an amorphous alloy, a threshold filter was then applied, set to display a signal only when the mean brightness is exceeded by three standard deviations. Finally, the images were inverted. Although the choice of the threshold filter is somewhat arbitrary, and accurate quantification cannot be made, the results are of qualitative, even semi-quantitative, significance. ${ }^{13,14}$

A shear band is about 20-30 nm wide. Figure 3(a) is a HRTEM image of rolled $\mathrm{Al}_{90} \mathrm{Fe}_{5} \mathrm{Gd}_{5}$, containing both a part of a shear band and its neighboring, undeformed, matrix. Nanocrystalline particles, 4-6 nm in diameter, are observed within the shear band. Figure 4(a) is an image obtained at a defocus value of $-200 \mathrm{~nm}$ and filtered as described above. From it, a threshold-filtered and inverted image was obtained [Fig. 5(a)]. Lowdensity, nanoscale defects are observed predominantly in the shear bands near the boundary with the undeformed matrix. These defects will be referred to as nanovoids. ${ }^{13,14}$ Few such defects are observed in interior of the shear band or in the undeformed matrix.

Figure 3(b) is a HRTEM image of rolled $\mathrm{Al}_{86.8} \mathrm{Ni}_{3.7} \mathrm{Y}_{9.5}$ containing both a part of a shear band and its neighboring undeformed matrix. Again, the shear band appears bright and the undeformed region dark. No nanocrystals are observed within the shear band. Figure 4(b) is an image obtained at a defocus value of $-200 \mathrm{~nm}$ and filtered, as described above. From Fig. 4(b), a threshold-filtered and 


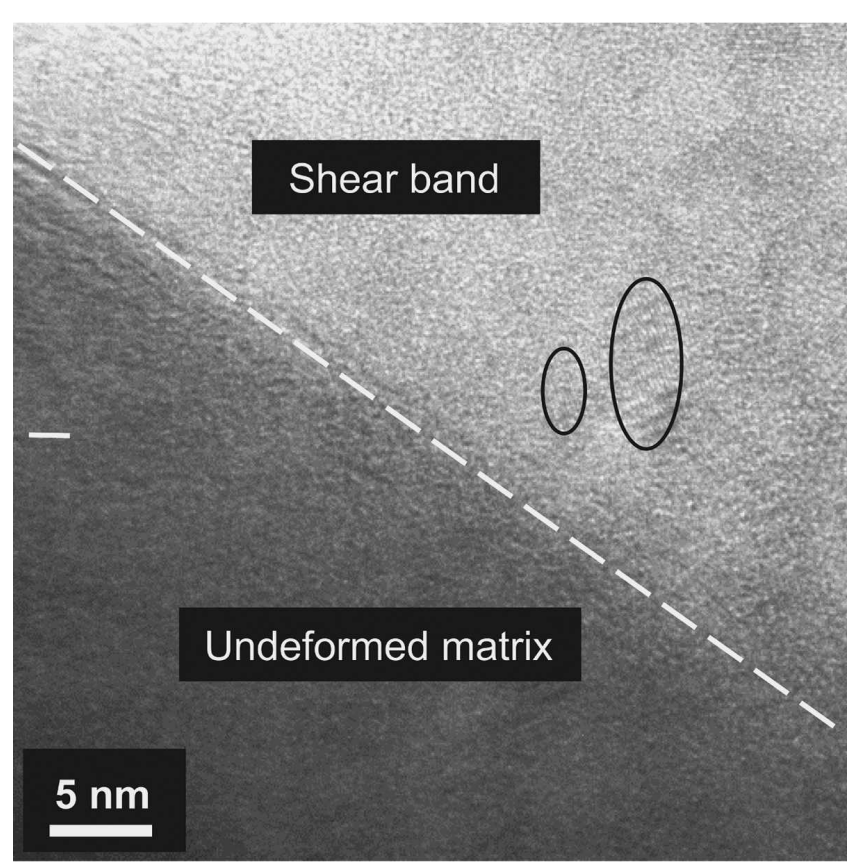

(a)

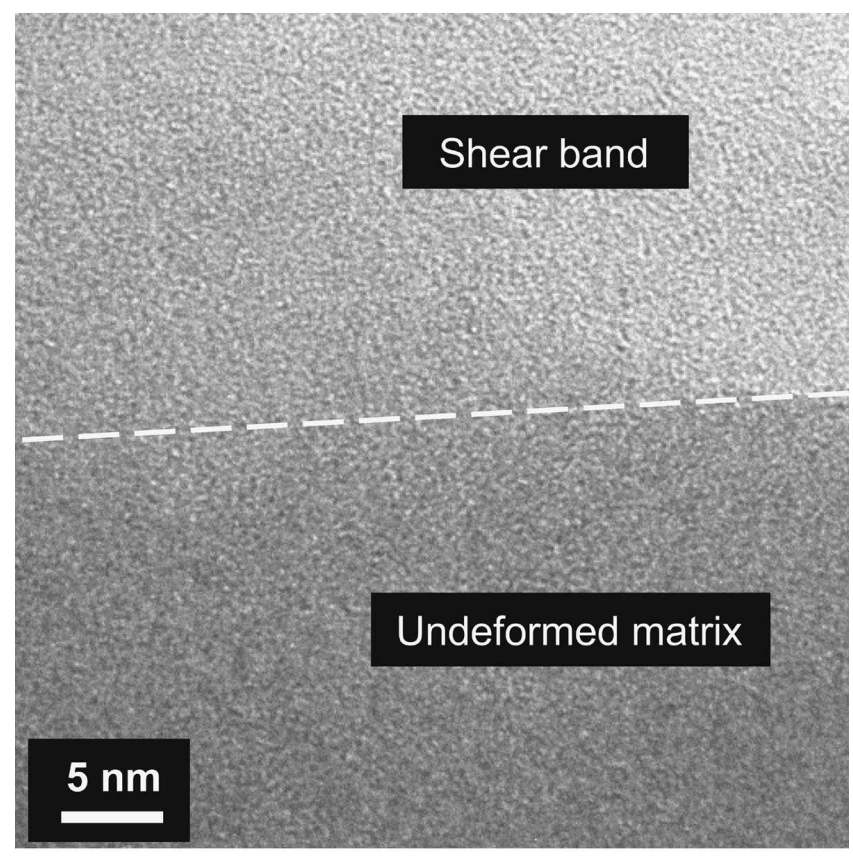

(b)

FIG. 3. HRTEM images of a part of a shear band (bright) and its neighboring undeformed matrix (dark) in (a) rolled $\mathrm{Al}_{90} \mathrm{Fe}_{5} \mathrm{Gd}_{5}$ and (b) rolled $\mathrm{Al}_{86.8} \mathrm{Ni}_{3.7} \mathrm{Y}_{9.5}$. The dash lines indicate the boundary between a shear band and an undeformed matrix.

inverted image was obtained [Fig. 5(b)]. Evidently, the nanovoids are located mainly in the shear band and distributed uniformly.

If the results for the two rolled amorphous ribbons are compared, it is evident that imaging features viewed by this technique result from the structural details of the

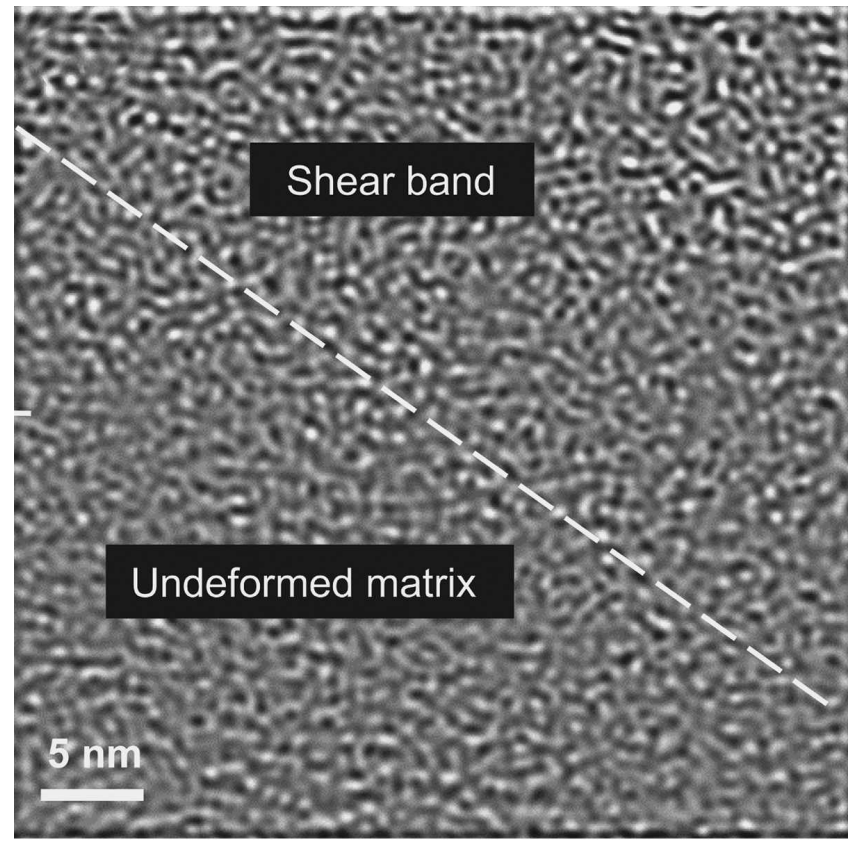

(a)

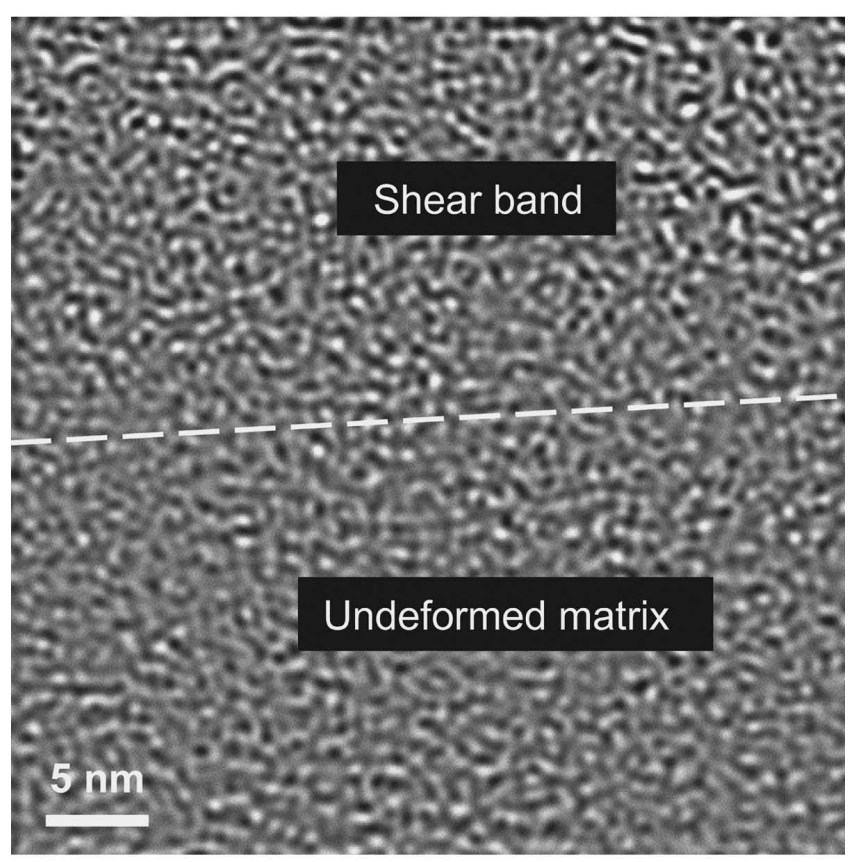

(b)

FIG. 4. (a, b) Images corresponding to Figs. 3(a) and 3(b), respectively, but defocused $-200 \mathrm{~nm}$, Fourier filtered to pass $0.5<k<$ $1.5 \mathrm{~nm}^{-1}$.

materials, rather than from a smaller sample thickness at the shear bands. This comparison also lends support to the effectiveness of the method. However, it must be mentioned that a comparison of the absolute density of defects in different samples [Figs. 5(a) and 5(b)] is not possible. Despite the fact that the images were processed in the same way, the imaging conditions for Figs. 5(a) 


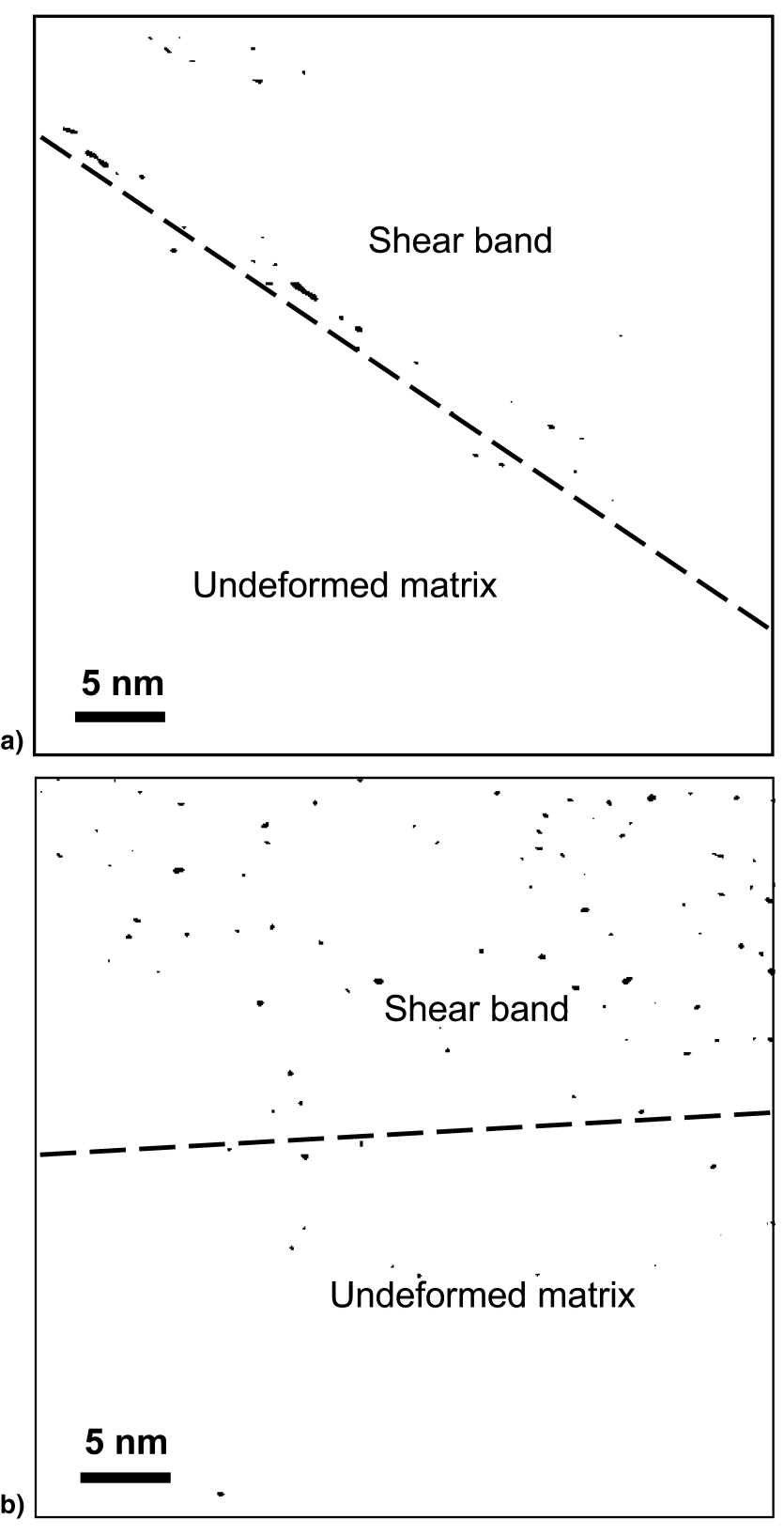

FIG. 5. (a, b) Images corresponding to Figs. 4(a) and 4(b), respectively, but threshold filtered and inverted.

and 5(b) were not identical, resulting in incomparability in the intensity. Although the threshold filters were set using the same criterion, the standard deviations are different for the two samples. It is the comparison of variations within each sample that is significant.

It has been demonstrated that mechanically-induced nanocrystallization is dependent on alloy composition. Bending resulted in the precipitation of the nanocrystalline $\mathrm{Al}$ particles in amorphous $\mathrm{Al}_{90} \mathrm{Fe}_{5} \mathrm{Gd}_{5}$ alloy ${ }^{4,12}$ but failed to induce nanocrystallization in amorphous $\mathrm{Al}_{85} \mathrm{Ni}_{10} \mathrm{Ce}_{5} \cdot{ }^{4}$ Also, ball milling for $1 \mathrm{~h}$ could form nanocrystallites in amorphous $\mathrm{Al}_{90} \mathrm{Fe}_{5} \mathrm{Gd}_{5}, \mathrm{Al}_{90} \mathrm{Fe}_{5} \mathrm{Ce}_{5}$, and $\mathrm{Al}_{87} \mathrm{Fe}_{8.7} \mathrm{Gd}_{4.3}$, while ball milling, even for $5 \mathrm{~h}$, could not cause the formation of nanocrystallites in amorphous $\mathrm{Al}_{85} \mathrm{Ni}_{5} \mathrm{Y}_{10}{ }^{1}$ Such differences are used here to help us understand the mechanisms of nanocrystallization induced by mechanical deformation.

The observed phenomena are best explored by studying the structural nature of the shear bands. The direct observation of defects in amorphous alloys is more challenging than in crystalline materials. Using a recently developed quantitative HRTEM technique, the present work clearly demonstrates a substantial difference between the shear bands of a deformed amorphous alloy that exhibits nanocrystallization and another alloy that does not. In rolled $\mathrm{Al}_{90} \mathrm{Fe}_{5} \mathrm{Gd}_{5}$, the interior of the shear bands contains few nanovoids while the boundary zone between the shear band and undeformed region contains most nanovoids [Fig. 5(a)]. In rolled $\mathrm{Al}_{86.8} \mathrm{Ni}_{3.7} \mathrm{Y}_{9.5}$, the shear bands contain a higher density of nanovoids than the surrounding undeformed region [Fig. 5(b)]. Li et al., ${ }^{14}$ using the same method for a Zr-based amorphous alloy, reported a higher density of nanovoids in the shear bands than in the amorphous matrix. These shear bands were at the tip of cracks developed during the electropolishing. The defect distribution they observed is similar to that of the rolled $\mathrm{Al}_{86.8} \mathrm{Ni}_{3.7} \mathrm{Y}_{9.5}$ alloy in the present work. We note that no nanocrystals were observed in Ref. 14.

In an investigation of shear bands in deformed, amorphous nickel-phosphorus thin films, using axially aligned, dark-field TEM, Donovan and Stobbs ${ }^{17}$ observed dilated bands forming in both compression and tension. They also observed a large small-angle scattering signal for bands obtained in tension, which they attributed to voids. They argued that the shear bands were dilated in both compression and tension, which is required for atomic motion to take place. Recently, using real-time diffraction using synchrotron radiation, Hajlaoui et al. ${ }^{18}$ observed a $37 \%$ increase in the amount of free volume when subjecting Zr-based metallic glasses to cold deformation. Their measurement was based on the assumption that the magnitude of the wave vector at which the diffraction pattern has a maximum is proportional to the cubic root of the number density. Using positron annihilation spectroscopy and differential scanning calorimetry (DSC), Kanungo et al. ${ }^{19}$ observed an increase in free volume in $\mathrm{Cu}$ - and $\mathrm{Zr}$-based bulk metallic glasses after rolling at room temperature. Sundar Daniel et al. ${ }^{20}$ reported similar observation in a $\mathrm{Zr}$-based bulk metallic glass at different stages of tensile creep at elevated temperature around its glass transformation temperature.

Our previous work ${ }^{12}$ showed that bending of amorphous $\mathrm{Al}_{90} \mathrm{Fe}_{5} \mathrm{Gd}_{5}$ alloy ribbon at room temperature induced nanocrystallization only in the compressive region but not in the tensile region. Furthermore, the shear bands in the compressive and tensile regions, imaged 
using HRTEM with Fourier transform filtering, exhibited different nanovoid distributions. In the compressive region, nanovoids were observed mainly in the shear bands near the boundary with undeformed region, whereas in the tensile region, the shear bands contained a uniform, higher, density of nanovoids than the undeformed matrix. This correlation between the defect distribution and nanocrystallization is analogous to the present results. Below, we argue for a causality relationship between the absence of nanovoids and nanocrystallization. This is plausible because the average separation between nanocrystallites in $\mathrm{Al}_{90} \mathrm{Fe}_{5} \mathrm{Gd}_{5}$ is several orders of magnitude larger than the average separation between nanovoids in shear bands in $\mathrm{Al}_{86.8} \mathrm{Ni}_{3.7} \mathrm{Y}_{9.5}$. Therefore, it is unlikely that the nanocrystallites would affect nanovoid formation.

We note that $\mathrm{Al}_{90} \mathrm{Fe}_{5} \mathrm{Gd}_{5}$ and $\mathrm{Al}_{86.8} \mathrm{Ni}_{3.7} \mathrm{Y}_{9.5}$ $\left(\mathrm{Al}_{85} \mathrm{Ni}_{5} \mathrm{Y}_{10}\right)$ have different stability against thermal devitrification, with first crystallization temperatures of 220 and $280{ }^{\circ} \mathrm{C}$, respectively. ${ }^{1}$ However, this small difference in thermal stability seems to be less relevant to deformation-induced crystallization; Kim et al. ${ }^{9}$ observed nanocrystallization induced by nanoindentation at room temperature in $\mathrm{Zr}_{52.5} \mathrm{Cu}_{17.9} \mathrm{Ni}_{14.6} \mathrm{Al}_{10} \mathrm{Ti}_{5}$ bulk metallic glass, whose first crystallization temperature is much higher, $431{ }^{\circ} \mathrm{C}^{23}$ The first thermal crystallization product in $\mathrm{Al}_{90} \mathrm{Fe}_{5} \mathrm{Gd}_{5}$ is primary $\mathrm{Al}$ whereas in $\mathrm{Al}_{85} \mathrm{Ni}_{5} \mathrm{Y}_{10}$ it is not. ${ }^{1}$ However, primary crystallization is not a requirement for deformation-induced crystallization; the first crystallization products in $\mathrm{Zr}_{52.5} \mathrm{Cu}_{17.9}$ $\mathrm{Ni}_{14.6} \mathrm{Al}_{10} \mathrm{Ti}_{5}$ are $\mathrm{Zr}_{2} \mathrm{Ni}$ and $[\mathrm{Ni},(\mathrm{Zr}, \mathrm{Ti})]$, not primary phases. $^{23}$

Amorphous alloys are known to have a varying amount of excess free volume. Regions with high free volume are expected to have a lower strength. Steif et al. $^{21}$ and argon, ${ }^{22}$ in their free volume creation models, suggested that a pre-existing, narrow, "weakened band" precedes the localization of plastic flow. The weakened band may develop into a highly locally deformed band, i.e., shear band, during mechanical deformation. In a bent sample, the shear strain within the shear band can be as high as $10^{2} \%$ to $10^{3} \%$. $^{4}$ Therefore, a large number of the atoms within shear bands is subject to local displacements. Thus, atomic dilation in the shear bands is the likely cause of enhanced atomic mobility. We suggest, as we did in our comparison of compressive and tensile regions in $\mathrm{Al}_{90} \mathrm{Fe}_{5} \mathrm{Gd}_{5},{ }^{12}$ that the cause of the absence of nanocrystallization in the $\mathrm{Al}_{86.8} \mathrm{Ni}_{3.7} \mathrm{Y}_{9.5}$ alloy is that free volume condenses into nanovoids during deformation, even under compression, resulting in its reduced availability to enhance atomic transport. A possible reason for the difference in nanovoid formation under compression between the alloys could be a difference in surface tension and hence in the driving force for free-volume coalescence. The voids at the boundary zone of the shear bands in rolled $\mathrm{Al}_{90} \mathrm{Fe}_{5} \mathrm{Gd}_{5}$ alloy may be a result of shrinkage due to nanocrystallization within the shear bands.

\section{CONCLUSIONS}

Through TEM and HRTEM techniques, the effect of rolling at room temperature on the microstructures of amorphous $\mathrm{Al}_{90} \mathrm{Fe}_{5} \mathrm{Gd}_{5}$ and $\mathrm{Al}_{86.8} \mathrm{Ni}_{3.7} \mathrm{Y}_{9.5}$ alloys was investigated. The main results can be summarized as follows.

1) In rolled amorphous $\mathrm{Al}_{90} \mathrm{Fe}_{5} \mathrm{Gd}_{5}$, nanocrystallization occurred at shear bands, whereas no nanocrystallites formed in rolled amorphous $\mathrm{Al}_{86.8} \mathrm{Ni}_{3.7} \mathrm{Y}_{9.5}$.

2) Combining HRTEM with Fourier transform and filtering techniques allowed nanovoids in the shear bands to be imaged. In rolled $\mathrm{Al}_{90} \mathrm{Fe}_{5} \mathrm{Gd}_{5}$, nanovoids are concentrated in the shear bands, near the boundary with the undeformed matrix, but they are rare in the interior of the shear bands. In rolled $\mathrm{Al}_{86.8} \mathrm{Ni}_{3.7} \mathrm{Y}_{9.5}$, the shear bands contain a higher, evenly distributed concentration of nanovoids than the surrounding undeformed region.

3) The preferential precipitation of nanocrystallites in rolled $\mathrm{Al}_{90} \mathrm{Fe}_{5} \mathrm{Gd}_{5}$ is attributed to a kinetic effect due to the uniformly distributed free volume in the shear bands.

\section{ACKNOWLEDGMENTS}

This work was funded by the United States National Science Foundation (NSF), Grant No. DMR-0314214. The JEOL-2010F HRTEM used in this work was funded by NSF through the Grant No. DMR-9871177 and is operated by the Electron Microbeam Analysis Laboratory at the University of Michigan, Ann Arbor, MI.

\section{REFERENCES}

1. Y. He, G.J. Shiflet, and S.J. Poon: Ball milling-induced nanocrystal formation in aluminum-based metallic glasses. Acta Metall. Mater. 43, 83 (1995).

2. G.J. Fan, M.X. Quan, Z.Q. Hu, W. Löser, and J. Eckert: Deformation-induced microstructural changes in $\mathrm{Fe}_{40} \mathrm{Ni}_{40} \mathrm{P}_{14} \mathrm{~B}_{6}$ metallic glass. J. Mater. Res. 14, 3765 (1999).

3. J. Xu and M. Atzmon: Temperature dependence of deformationassisted crystallization in amorphous $\mathrm{Fe}_{78} \mathrm{~B}_{13} \mathrm{Si}_{9}$. Appl. Phys. Lett. 73, 1085 (1998).

4. H. Chen, Y. He, G.J. Shiflet, and S.J. Poon: Deformation-induced nanocrystal formation in shear bands of amorphous alloys. Nature 367, 541 (1994).

5. A. Ogura, M. Sato, R. Tarumi, M. Shimojo, K. Takashima, and Y. Higo: Formation of nano-sized crystals during plastic deformation in amorphous alloys, in Structure and Mechanical Properties of Nanophase Materials-Theory and Computer Simulations vs. Experiment, edited by D. Farkas, H. Kung, M. Mayo, H. Van Swygenhoven, and J. Weertman (Mater. Res. Soc. Symp. Proc. 634, Warrendale, PA, 2001), p. B1.10.1. 
6. H.J. Jin, F. Zhou, L.B. Wang, and K. Lu: Effect of plastic deformation on thermal stability in metallic glasses. Scripta Mater. $\mathbf{4 4}$, 1083 (2001).

7. Y.H. Kim, G.S. Choi, I.G. Kim, and A. Inoue: High-temperature mechanical properties and structural change in amorphous Al-NiFe-Nd alloys. Mater. Trans. JIM 37, 1471 (1996).

8. M.C. Gao, R.E. Hackenberg, and G.J. Shiflet: Deformationinduced nanocrystal precipitation in Al-base metallic glasses. Mater. Trans. JIM 42, 1741 (2001).

9. J.J. Kim, Y. Choi, S. Suresh, and A.S. Argon: Nanocrystallization during nanoindentation of a bulk amorphous metal alloy at room temperature. Science 295, 654 (2002).

10. W.H. Jiang, F.E. Pinkerton, and M. Atzmon: Effect of strain rate on the formation of nanocrystallites in an Al-based amorphous alloy during nanoindentation. J. Appl. Phvs. 93, 9287 (2003).

11. A.A. Csontos and G.J. Shiflet: Formation and chemistry of nanocrystalline phase formed during deformation in aluminumrich metallic glasses. Scripta Mater. 9, 281 (1997).

12. W.H. Jiang and M. Atzmon: The effect of compression and tension on shear-band structure and nanocrystallization in amorphous $\mathrm{Al}_{90} \mathrm{Fe}_{5} \mathrm{Gd}_{5}$ : A high-resolution transmission-electron-microscopy study. Acta Mater. 51, 4095 (2003).

13. D.P. Miller and J.M. Gibson: Connecting small-angle diffraction with real-space images by quantitative transmission electron microscopy of amorphous thin-films. Ultramicroscopy 74, 221 (1998).

14. J. Li, Z.L. Wang, and T.C. Hufnagel: Characterization of nanometer-scale defects in metallic glasses by quantitative highresolution transmission electron microscopy. Phys. Rev. B $\mathbf{6 5}$, 144201 (2002)
15. C.A. Pampillo: Localized shear deformation in a glassy metal. Scripta Metall. 6, 915 (1972).

16. W.B. Pearson: A Handbook of Lattice Spacing and Structures of Metals and Alloys (Pergamon Press, London, U.K., 1958), p. 124.

17. P.E. Donovan and W.M. Stobbs: The structure of shear bands in metallic glasses. Acta Metall. 29, 1419 (1981).

18. K. Hajlaoui, T. Benameur, G. Vaughan, and A.R. Yavari: Thermal expansion and indentation-induced free volume in $\mathrm{Zr}$-based metallic glasses measured by real-time diffraction using synchrotron radiation. Scripta Mater. 51, 843 (2004).

19. B.P. Kanungo, S.C. Glade, P. Asoka-Kumar, and K.M. Flores: Characterization of free volume changes associated with shear band formation in $\mathrm{Zr}$ - and $\mathrm{Cu}$-based bulk metallic glasses. Intermetallics 12, 1073 (2004).

20. B.S. Sundar Daniel, M. Heilmaier, B. Bartusch, J. Kanzow, K. Günther-Schade, K. Rätzke, J. Eckert, and F. Faupel: Free volume evolution in bulk metallic glass during high temperature creep, in Supercooled Liquids, Glass Transition and Bulk Metallic Glasses, edited by T. Egami, A.L. Greer, A. Inoue, and S. Ranganathan (Mater. Res. Soc. Symp. Proc. 754, Warrendale, PA 2003), p. 293.

21. P.S. Steif, F. Spaepen, and J.W. Hutchinson: Strain localization in amorphous metals. Acta Metall. 30, 447 (1982).

22. A.S. Argon: Plastic deformation in metallic glasses. Acta Metall. 27, 47 (1979).

23. J.G. Wang, B.W. Choi, T.G. Nieh, and C.T. Liu: Crystallization and nanoindentation behavior of a bulk $\mathrm{Zr}-\mathrm{Al}-\mathrm{Ti}-\mathrm{Cu}-\mathrm{Ni}$ amorphous alloy. J. Mater. Res. 15, 798 (2000). 